\title{
Mobile Augmented Reality Client as a UX Method for Living Lab's User Involvement Tool
}

\author{
Paula Alavesa ${ }^{1}$, Minna Pakanen ${ }^{1 \& 2}$, Arttu Niemelä ${ }^{3}$, Weiping Huang ${ }^{1}$, Satu Väinämö ${ }^{4}$, Lotta \\ Haukipuro $^{5}$, Leena Arhippainen ${ }^{1 \& 2}$ and Timo Ojala \\ ${ }^{1}$ Center for Ubiquitous Computing, University of Oulu ${ }^{2}$ INTERACT Research Unit, University of Oulu ${ }^{3}$ Trä Group Oy, \\ 00160 Helsinki, Finland ${ }^{4}$ Centre for health and technology, University of Oulu ${ }^{5} \mathrm{GenZ}$ project, University of Oulu \\ Oulu, Finland \\ firstname.lastname@oulu.fi
}

\begin{abstract}
This paper introduces an augmented reality application, AR PATIO, which was developed for an existing user involvement tool that is a part of a living lab. Augmented reality contents can be projected on-site to visualize change in a comprehensible and visual way. The aim of our application is to provide new methods for involving citizens in the innovation, co-creation, and evaluation of services and products in a living lab context. Our solution gives users the possibility to express their reactions by leaving location-based comments and feedback when using augmented reality. AR PATIO was evaluated as a part of a bigger user-experience study in which virtual reality and mobile clients were also tested. However, in this paper, we focus on the results from an AR use case. According to our UX study with 14 participants, AR PATIO created a positive experience. It was regarded as empowering, playful, innovative, and useful.
\end{abstract}

\section{CCS CONCEPTS}

- Human-centered computing - Human computer interaction (HCI); Mixed/augmented reality

\section{KEYWORDS}

Augmented reality, living lab, user involvement, user experience.

\section{ACM Reference format:}

Paula Alavesa, Minna Pakanen, Arttu Niemelä, Weiping Huang, Satu Väinömö, Lotta Haukipuro, Leena Arhippainen and Timo Ojala. 2018. Mobile Augmented Reality Client as a UX Method for Living Lab's User Involvement Tool. In Proceedings of ACM Mindtrek'18. ACM, New York, NY, USA, 8 pages. https://doi.org/10.1145/3275116.3275147

\section{Introduction}

Living labs are becoming popular ways to involve users in the innovation and evaluation process for products and services. In the literature, living labs are referred to in various ways. The living lab has been described as a user-centered innovation environment based on daily practice and research. The aim of the living lab is sustainable value creation by involving users in an open innovation process in a real-life context [6]. It can also be considered a community-based, user innovation creation with business stakeholders involved either online or offline [5]. In addition, a living lab can be seen as a network that integrates both user-centered research and open innovation [20]. What these definitions have in common is that they include users as equal cocreators with other participants and experiments in real-world settings [2]. Compared to field trials or user testing, a living lab aims to involve users in all stages of the product development lifecycle [5]. The challenge is in reaching people amidst their daily lives in a way that the surveys are projected in a comprehendible manner. This is where new technologies, such as augmented reality (AR) and virtual reality (VR), can help, since they provide a fully immersive or partly projected, realistic 3D content overlay to the physical world.

Our motivation was to develop a mobile augmented reality (MAR) application, which can enhance user participation for cocreation and evaluation of new products and services as a part of living lab activities. Our AR PATIO was developed to be a part of OULLab's (OULU Urban Living Lab) online user community and user involvement tool, PATIO [13, 14]. To evaluate user experiences (UX) with our MAR application, we had a real, usercentered innovation case to study. As the exhibition of a local zoological museum at the University of Oulu closed, and its future became unclear, there was a need for different stakeholders to consider how museum content could be preserved in the future. One idea was to virtually conserve the museum as a part of the virtual campus [17] by creating a new visit experience using VR and AR technologies.

This paper's focus is on AR PATIO results from a user experience point of view. We present the development of our AR PATIO and how it can be used as a UX method and as a part of our PATIO user involvement tool. In addition, we present the findings from a qualitative UX study. 


\section{Related Work}

Citizen participation is becoming crucial in efficient design and development of services, products, and city plans that satisfy the end-users, i.e. the citizens. This makes it necessary to provide the right digital tools to facilitate their involvement [11]. AR is a potential interface for linking digital information directly with the physical world [21]. In 2007, it was estimated that ten to twenty percent of living labs utilized AR (or other new technologies) [22], and in 2018, the European Network of Living Labs reported almost 400 living labs as members [9]. Large-scale MAR applications are not new or uncommon; early work on the topic was already done in 1999 [13]. However, there is still demand for investigating MAR applications for citizen participation, especially since the technology is now maturing to a stage where it can be used with most mobile phones.

UX is defined as a "person's perceptions and responses that results from the use and/or anticipated use of a product, system or service" [14]. UX has been seen as a significant factor for a products' success $[15,20]$. Therefore, it is important to develop and use systematic, low-cost methods for UX evaluation and utilize the collected information in the early phase of the development process [26, 27]. MAR has the potential to benefit user experience studies because it makes it possible to record experiences before, during, and after the use of products or services [26].

\subsection{Mobile Augmented Reality}

AR merges virtuality into the real world or, at least, aims to create an illusion of such a merge [7]. Virtuality is often perceived as computer-generated graphics that provide a visual experience. However, AR systems may also provide other sensory experiences like audio and haptics. The real world is the physical environment that the user experiences without the use of any devices, and it is sometimes referred to as the real reality (RR) [8]. In addition to combining real and virtual, AR is interactive in real-time, and the projected contents can be $3 \mathrm{D}[1,2]$. MAR makes AR experiences mobile and ubiquitously accessible.

There are three major technological challenges in developing MAR: 1) tracking, 2) displaying, and 3) interaction. Tracking seeks solutions to how computers can understand physical reality and position digital contents appropriately. Displaying involves showing the combination of virtual and real to users. Interaction is also tricky; in order to benefit from AR, novel input methods are required. In addition, networking, data management, and battery consumption in mobile devices are issues with MAR [8, 11]. These challenges also reflect the three key technical requirements of AR: displays, interaction, and tracking. Displays are needed to present the combination of real and virtual to the user. Interaction requires novel input techniques to manipulate the virtual information. Tracking techniques are needed to measure the real world and align the virtual information with it [2]. The same definition and technical requirements apply for basic AR and MAR. However, mobility adds more demands in terms of scalability and performance [15]. In practice, an MAR system should work on a large scale, globally at best, and execute in real time on mobile devices.

\subsection{Involving Users}

Application areas for AR are numerous spanning from games such as Pokémon GO [29] to applications for citizen participation [12, 25].

Allen et al. presented a smartphone application, which displayed architectural designs over existing architecture in AR [1]. The application was developed to involve users in urban planning. It had a graphical user interphase (GUI) with a 7-step smiley-face scale for users to rate the displays' designs, and the ratings were made available for stakeholders in urban planning. According to Allen et al. [1], using MAR when presenting architectural designs for experts is common, but not much research is done with regards to public participation. Their results indicated that their system increased younger people's willingness to participate in urban planning, while willingness remained unchanged for older people. The application was generally considered useful for displaying architectural designs, but users questioned if the ratings would truly be considered by the stakeholders, which is a known issue in citizen participation $[1,21]$.

CityScope [25] is a tangible user interface (TUI) platform adaptable to different use cases, such as Hamburg's (Germany) refugee challenge, which adds to the discussion about designing MAR systems for user involvement. The system's basic idea is to display geographic information in a table for both experts and the public to use it to tackle various societal problems. It was also designed to have tangible objects for interaction, which represented, for example, buildings and building elements. CityScope is used in the Andorra Living Lab project to present geographical information in AR [25].

In the context of the refugee crisis, CityScope [25] was used to enable both experts and the public to find suitable locations to accommodate refugees. The system was later evaluated through SWOT analysis (strengths, weaknesses, opportunities and threats). Strengths included that authorities received high quality information based on citizens local knowledge and that the citizens felt they were actively participating in the process, which also built up acceptance towards refugee accommodation.

Gutiérrez et al. [12] describe a Pace of the City MAR application developed as part of a bigger project to establish a smart city platform in Santander, Spain that would ultimately engage citizens in city development and, thus, improve their lives. The authors also emphasized the need for infrastructure when creating such a platform. The sensing network used consisted of various sensors around the city. The Pace of the City aimed to visualize diverse data provided by the platform. The data included points-of-interest (POI) and real-time information on such things as traffic, cameras, and forecasts. The data were presented location- and context-sensitively, but users were also able to choose their preferences on what they wanted to explore. The MAR application was complemented by tags placed around the city. The system could then recognize the tag and provide contextual information for it. In addition, users' smart phones 
were harnessed to gather data on geographic location, temperature, and humidity. The users themselves were also able to provide data to the network, for example, by taking a picture of a hole they found in the pavement. A local newspaper was also linked to the system to deliver news information. Due to the system's ability to provide useful data in various ways - as well as involve authorities, researchers, and individuals - the authors saw the platform as promising. However, they raised concerns about the privacy of the users. Despite this Pace of the City provides an example of big scale citizen involvement tool, where MAR application was successfully used in an urban context.

KioskAR is a prototype for an AR game in which art students can collaborate with each other [33]. The approach with KioskAR is more playful than with the preceding two examples. Users of the game establish AR kiosks in physical locations where they can present artworks, such as 3D models, videos, or photos. Other users' kiosks can be visited by moving to the according physical location, and users can interact with KioskAR by leaving comments. The users also compete for points that can be used to enhance a kiosk. Points are received for adding artworks to one's own kiosk and for visiting and interacting with other users' kiosks. Thus, the game rewards socializing.

The user interface (UI) of KioskAR includes a map view and an $A R$ view. The map view displays the environment and the kiosks on a $2 \mathrm{D}$ map to show a big picture of the game area. Tapping a kiosk on the map view gives a description of it. The AR view presents the kiosks in $3 \mathrm{D}$, and it is the main interface for interacting with them. In the AR view, tracking is achieved by combining GNSS positioning and IMU-based orientation. In addition, a spot view is a complementary mode to the map view, which presents available spots for kiosks on the map. There is also a kiosk view, which is used to browse available templates when establishing a new kiosk. Finally, a configuration view allows users to see and edit their profile information. Sekhavat [33] emphasized the importance of finding suitable evaluation methods, when evaluating AR application's usability and the users' sense of presence, since UX in AR has not been studied rigorously. The methods chosen to evaluate KioskAR were Handheld Augmented Reality Usability Scale (HARUS) [30] to evaluate usability and MEC Spatial Presence Questionnaire (MECSPQ) [37] to measure sense of presence. HARUS targets basic usability and not UX. MEC-SPQ, in turn, has been developed for either real-life or virtual environments, therefore it often needs to be adjusted $[23,40]$ for it to fit the purpose of AR research, where virtual and real-life are blended. This describes well the current status in evaluating AR applications, where most of the methods target usability or perception, not UX [7, 9, 26].

CityScope [25], Pace of the City [12] and KioskAR [33] highlight how MAR applications are a part of a larger system aiming for better smart city infrastructure and citizen or student involvement. In living labs, the aim is not only to provide a platform for citizen involvement but also to facilitate user involvement when developing new services or products [5].

\section{AR PATIO}

The AR PATIO is an application for answering location-based questionnaires complementing $\mathrm{AR}$ content. It is a client application for our user involvement tool, PATIO (a part of a OULLabs living lab $[13,14]$ ), and it is designed as an extension for Mobile PATIO. Although it is integrated with Mobile PATIO. The AR PATIO was developed with Unity (2017.3.0f3) as an Android application. The main component is a library for virtual and augmented reality (ALVAR 0.2.1) for Unity, which enables the augmented reality functionality. In addition, it utilizes the following: MapBox Unity SDK (1.3.0) [22], JSON .NET for Unity (2.0.1), and LeanTouch (1.3.4).

The UI elements and usage flow of using the application can be seen in Figures 1-3. Figure 1 shows how the AR PATIO is opened through Mobile PATIO. Map view (Fig. 2a) shows the user and questions based on their geolocation. To open a question, the user taps one "bubble" when it is in range (inside the radius of the range indicator). If a bubble is too far away, a dialog box opens to inform the user of this (Fig. 2b). This panel is also used for other dialogue, like thanking the user when all questions are answered. When a question is answered, its bubble indicator gets a darker shade.

a)

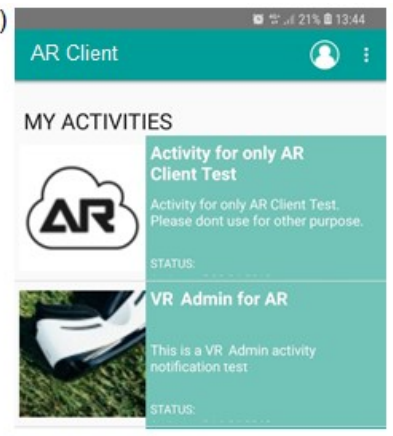

Figure 1: a) Activities in Mobile PATIO. b) The selected Activity in Mobile PATIO. In this activity, a user can join a forum discussion, answer a survey, open AR to browse AR content, and answer a question in AR view. 


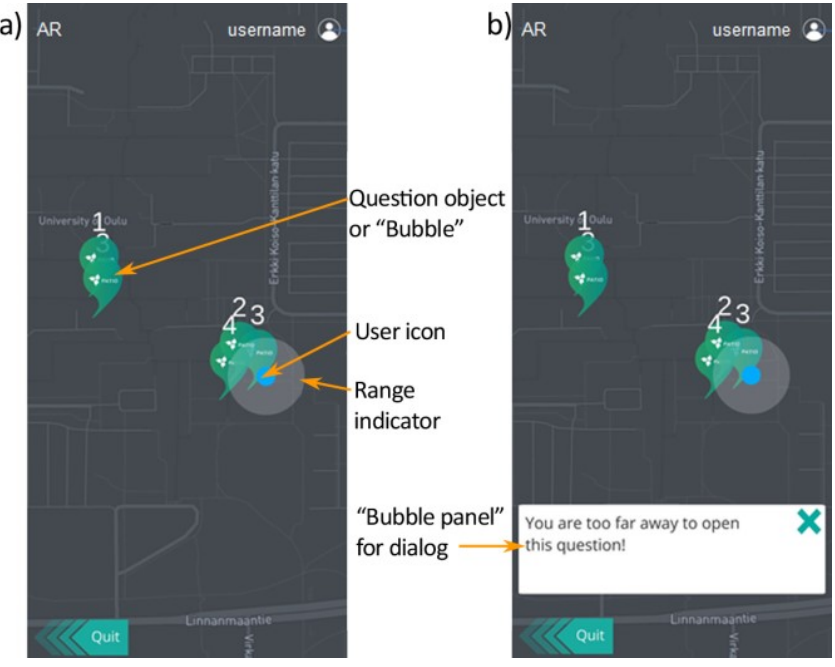

Figure 2: a) Map view in AR PATIO. b) Notification on a question being too far away.

Figures 3 and 4 show the AR PATIO's AR view, which displays a question and related AR content. The AR PATIO currently supports two types of questions: multiple choice (Fig. 3a) and a slider questions (Fig. 3b). The back-button takes the user back to Map view if they do not want to answer the question. The send-button sends the answer and takes the user to Map view.

To view AR content, the camera must be pointed at one of the various types of markers. One example is the binary marker, or the quick response (QR) code [34] (as shown in Fig. 3), which is the easiest target to use. Other types include point clouds and image markers [3, 4]. Targets bring the AR content into the AR PATIO. Essentially, targets are files that package the desired ALVAR-markers and the 3D-model placed at the target. In practice, targets are Unity AssetBundles [36]. This is a useful way to package both the ALVAR-target and 3D-model in a single file, which can be dynamically loaded. ALVAR does not officially support downloading targets on runtime, but AssetBundle is able to circumvent this limitation. AR PATIO uses point cloud markers.

\section{User Experience Study}

In this section, we present the procedure for the user experience study and report how participants experienced AR PATIO as a feedback collection method. In addition, we present user experiences and wishes for access to $3 \mathrm{D}$ animals with $\mathrm{AR}$ technology.
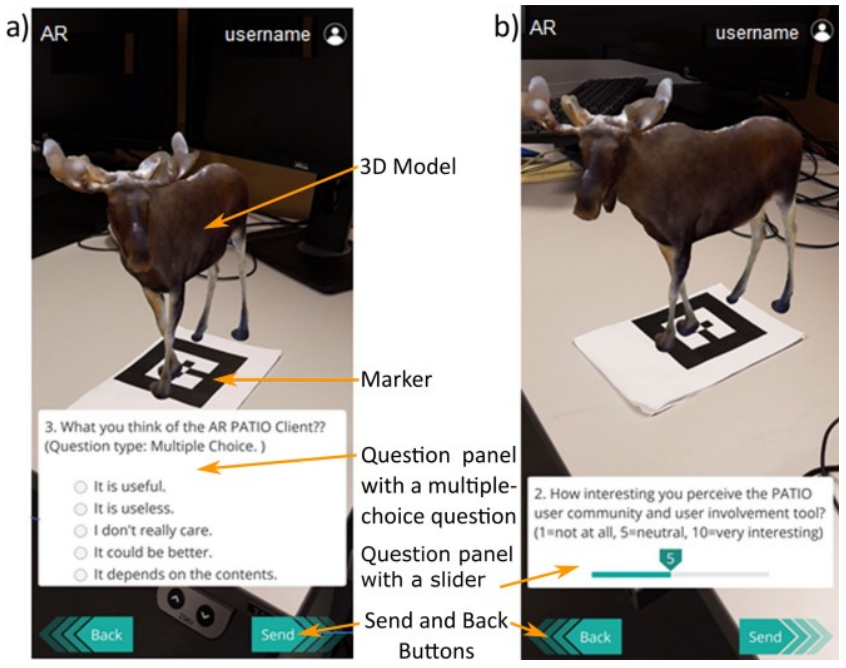

Figure 3: Questionnaire panels in a) AR view with a multiple-choice question and b) with a question slider.

\subsection{Test setup and participants}

We were interested in users' subjective experiences of how AR could be utilized for feedback collection. We studied how interesting, useful, and fun participants perceive the AR PATIO when observing and assessing AR content. We had a real, usercentered innovation case as a starting point: 3D scanned animals from a zoological museum were integrated into the campus of the University of Oulu, Finland using AR technology. The focus was to collect user experiences with location-aware questions in realtime.

We recruited test users from the PATIO online user community because we were testing new PATIO methods. Before the test session, participants answered a short pre-questionnaire using an online tool (Web PATIO [14]). None of the participants had prior experiences with AR PATIO. Participants' ages varied from 26 to 59 years, with a mean age of 36, and most of the users were female (8). The duration of each test session was approximately one hour, and users were interviewed and observed during the usage sessions. All sessions were video recorded and analyzed. In addition to interviews and observation, we collected user experiences by using the 5-point Likert Scale questionnaires and adjective cards selection method [35]. After the test, we also collected feedback from participants on our web tool via forum discussion and diary methods. 


\section{A short background questionnaire (paper format) \\ 2. Icebreaking and motivation for the test purpose: A short video ( $2 \mathrm{~min}$ ) of PATIO user involvement tool including four clients: Web, VR, Mobile and AR.}

3. Use of VR-PATIO:

A) Explore 3D environment and content and answer to questions in VR by gaze

B) After the use: select 4/42 adjective cards that depict your experiences relating to VR-PATIO and comment your selections.

C) Fill the Likert Scale questionnaire

(Ten zoological museum and 11 VR PATIO statements)

4. Use of AR-PATIO:

A) Explore 3D Content and answer to the questions B) After the use: select 4/42 adjective cards that depict your experiences relating to AR PATIO and comment your selections.

C) Fill the Likert scale questionnaire (11 zoological museum and 11 AR PATIO statements)

5. Use of Mobile PATIO:

A) a short use of mobile features e.g. browsing the activity information, answering to one survey question, joining to forum discussion)

C) Fill the Likert Scale questionnaire

(11 Web PATIO and ten Mobile PATIO statements)

6. Closing

Informing the use of online diary and participation of the forum discussion period after the test sessions. Thanks and small rewards.

Figure 4: Test procedure of the whole UX study. In practice, half of the participants tried AR PATIO first and VR PATIO second.

The AR PATIO was tested as a part of our larger study where we tested all four PATIO applications. The test procedure was organized as shown in Figure 4. Half of the participants used VRPATIO first and AR PATIO second and vice versa. Task 4 of the full study, "Use of AR PATIO," included four different actions. The participants began using AR PATIO with provided mobile phones that showed registered users' activities (Fig. 5 a). The users then selected the first activity: "Come and try our AR PATIO." After that, they could answer AR questions (Fig. 5b). At first, the map view was shown (Fig. 6a) where the users could see all nearby questions. When they were in range of a particular location, they could find the AR targets and answer the questions. The first AR content to which they were guided was a 3D gull (Fig. 6). After answering a survey question, the participants could spontaneously continue to the next target, which was a 3D lynx lying on a table (Fig. 7). Both targets were in the same meeting room, and they were positioned by using QR markers.

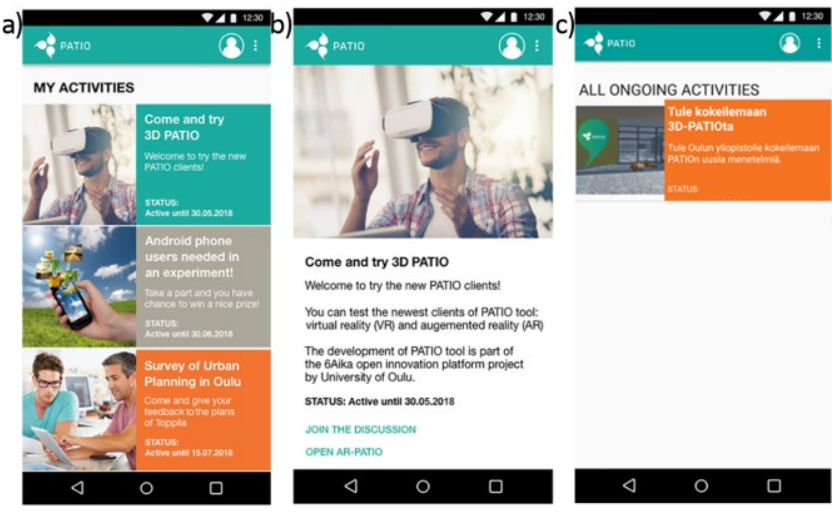

Figure 5: a) Mobile PATIO showing users' activities. When a user selects an activity, its available surveys are shown $b$ ). This study was set up so that the users had c) only one activity visible.

a)

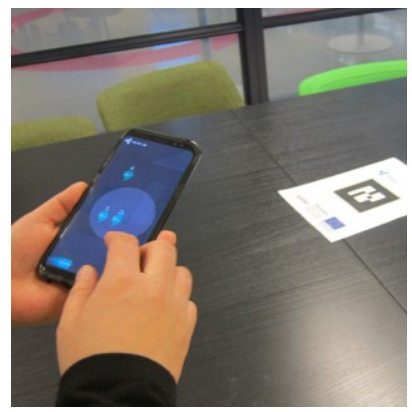

b)

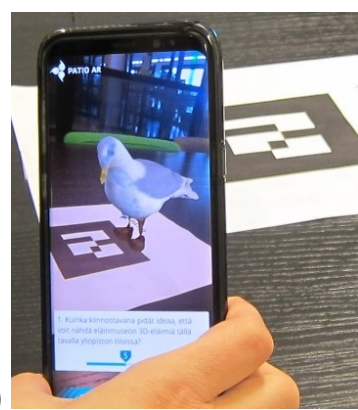

Figure 6: a) AR PATIO was launched from the Map view with question bubbles. b) When a user tapped a bubble, he/she could access the AR view. The user found AR content (gull) and answered the question.

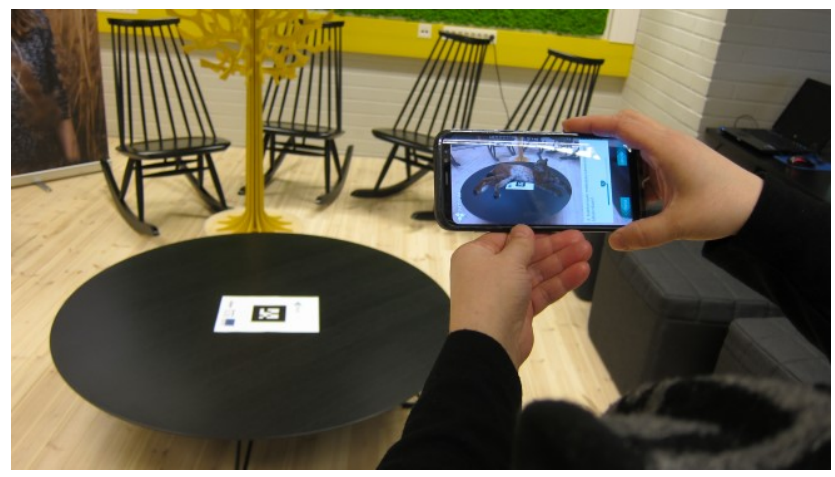

Figure 7: The second target was on a table. The user explored the AR content and answered a question. Here, a QR marker used to position a 3D lynx. 


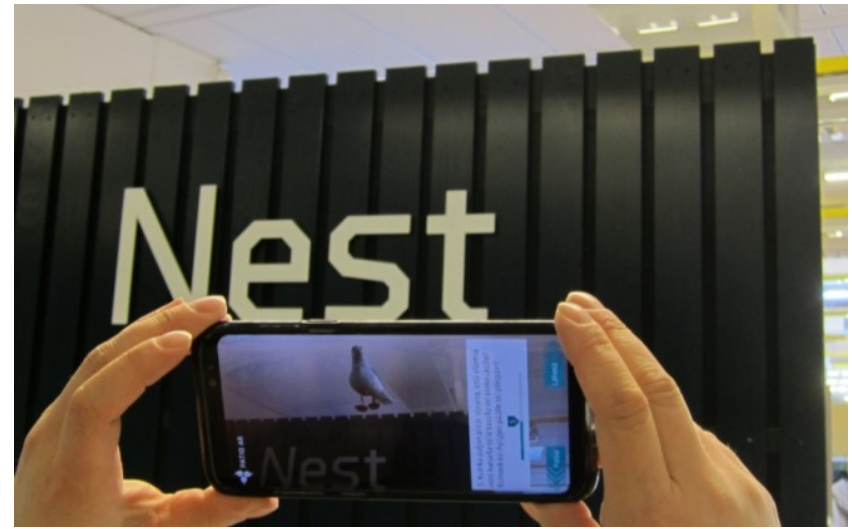

Figure 8: The third target was at the top of the wall. When the user pointed the device in the right direction, the AR content appeared, and the user could answer the question. Here, a point cloud of the environment was used as a marker.

The following two targets were located outside the meeting room but still inside the campus. We used both point cloud and QR markers to position the 3D content. The third target was by a "nest" sign on the wall (Fig. 8), and the fourth was situated by a wall art piece (Fig. 9). After a user had found all targets and answered the questions, he or she and the researchers went back to the meeting room. After an interview, the test procedure continued to the next phase: (Fig. 4b) "Select four adjectives that depict your experience with the use of AR PATIO."

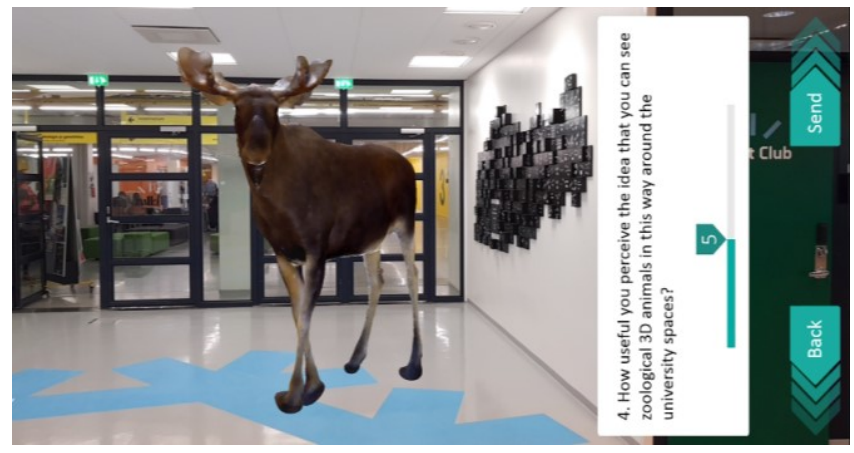

Figure 9: The fourth target, a moose, was positioned by a wall art piece. When the user pointed their device to that direction, the AR content ( $3 \mathrm{D}$ moose) appeared.

\subsection{User Experience Findings}

Participants' experiences with AR PATIO were very positive. As Likert Scale answers indicate (Fig. 10), participants felt that answering with AR PATIO was easy, fast, interesting, fun, and useful. Participants were excited to find AR content from the real campus area. They commented how this kind of method would be useful in different contexts, such as city planning, education, or entertainment. They also mentioned that being able to give feedback using a mobile phone in this manner would increase their involvement in design and evaluation of new services or systems through PATIO.

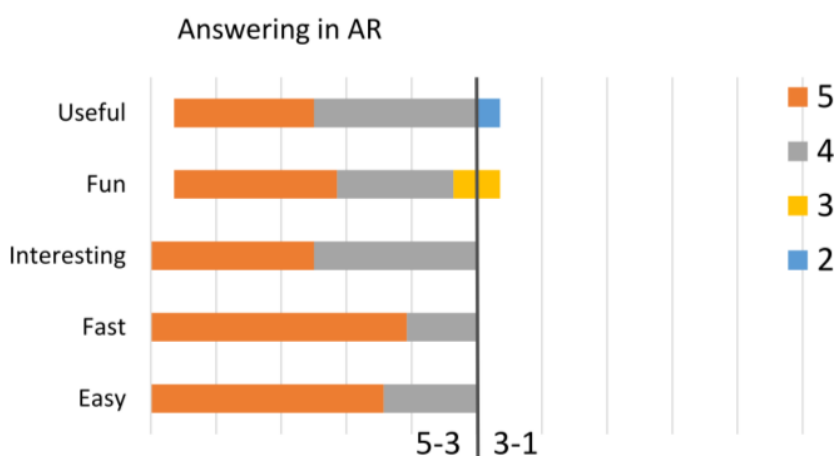

Figure 10: How users perceived answering in AR, shown by a diverging scale graph based on the results from a Likert scale questionnaire.

According to adjective selections (Fig. 11), the AR PATIO experience was empowering (7), playful (7), innovative (5), and useful (5).

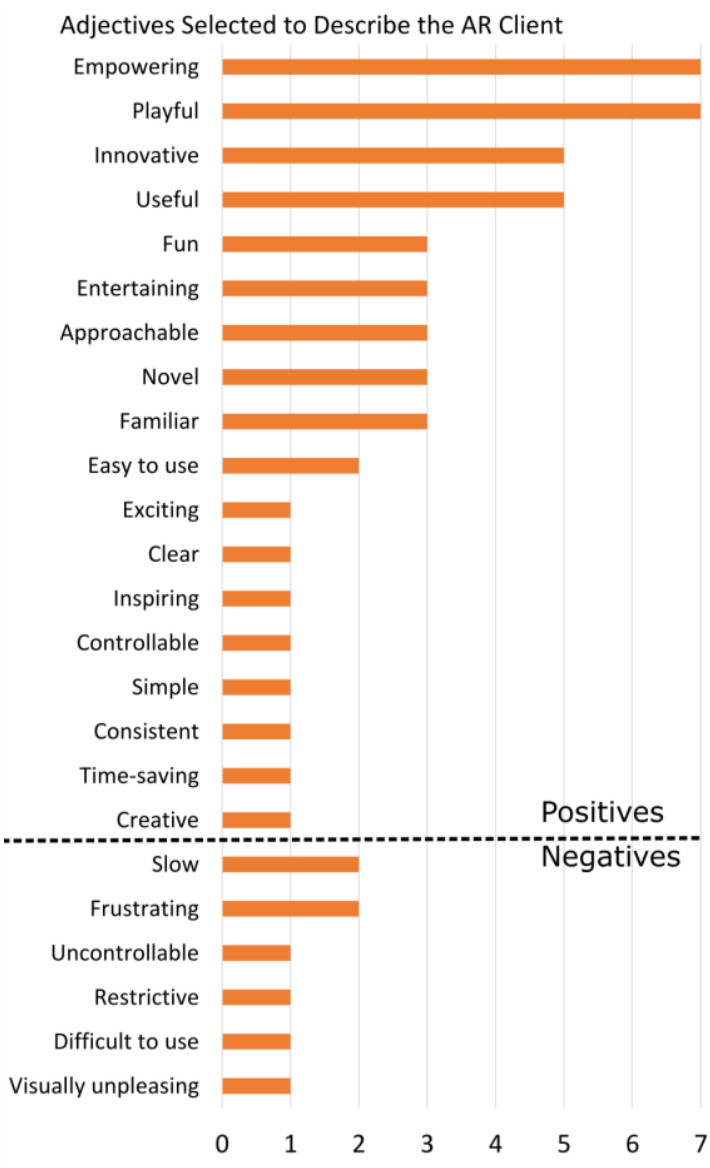

Figure 11: Adjectives selected to describe the AR PATIO. Each participant selected four adjectives out of a selection of 42,21 positives and 21 negatives. 
According to Likert Scale answers, experiencing the 3D animals from the zoological museum in the campus area using $A R$ technology was interesting, useful, and fun (Fig. 12). Many participants commented that there must be some rationale behind showing 3D zoological animals in the AR view. Just using the technology was not enough: there must be realistic cases that will give some utility to users. One case could involve learning and information sharing. Few participants commented specifically that being able to find realistic animals could help children to learn about nature.

Lighting conditions effect targeting with any AR application [28], in our case the users had difficulties in finding one of the 3D animals, the gull was close to a bright lamp. This is perhaps why two participants selected the adjective "frustrating" to describe the application (Figure 11).

Participants liked the possibility of exploring 3D animals from different sides and angles. This aspect is better for users than just a 2D image on a phone. Because AR content is browsed on personal mobile phones, participants thought that it would better to place 3D animals in different locations throughout the campus area, not only those centered in the zoological museum area. Likewise, they preferred animal placements in locations that seemed natural, like the gull at the top of a wall (high). Participants said that game-like, playful elements would be important to this kind of application in the future.

Observing 3D animals in AR

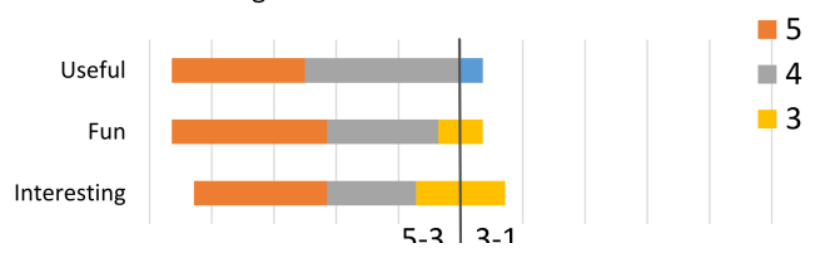

Figure 12: The use of AR technology in placing the 3D animals from the zoological museum into the campus area was described as interesting, useful, and fun, shown by a diverging scale graph based on the results from a Likert scale questionnaire.

Finding a way to utilize 3D models of zoological animals is very topical and an important issue at the University of Oulu, Finland. Because the local zoological museum exhibition has been closed, most of the animals have been placed in storage. Participants, who were familiar with the exhibition, missed the animals because they had visited often. They were enthusiastic about the idea of an AR and VR zoological museum where they could also access information on the animals, their behaviors, evolution, and sounds.

\section{Conclusion}

This paper presents an augmented reality client developed for a user involvement tool. The aim of the client is to provide a new method for a living lab context when involving citizens into the innovation, co-creation, and evaluation of services and products. AR PATIO gives users the possibility to express location-based comments and feedback while observing their environment through AR. According to our user study with 14 participants, AR PATIO was a very positive experience, and it was regarded as empowering, playful, innovative, and useful.

The concept of playfulness came across in much of the feedback. Participants were very enthusiastic about the AR PATIO, and they would have liked to find more AR content, in our case, more animals nested around campus. They commented that this kind of method is exciting and engaging because using the system with a mobile phone was easy and finding animals felt adventurous. They compared the experience to finding Pokémon when playing Pokémon Go.

\subsection{Limitations and Future Work}

Our study suffers from a small sample of users, though we aimed at complementing this limitation by collecting rich material. Animals were projected whimsically in AR view: the gull in Figure 8 was placed on top of a sign stating, "Nest." This may have contributed to the application being perceived as "playful." On the other hand, this kind of blending of virtual items and physical space is commonplace and unique for AR applications.

This study presents AR PATIO results from a user experience point of view not in terms of usability or visual design, which are both undeniably important aspects of the comprehensive UX. AR PATIO is, however, a reliably functioning application where the basic usability issues have already been polished out. The early evaluation of the AR PATIO was conducted in a city context [24], which shows that the application also works outdoors when point clouds are used as markers for AR content.

\section{ACKNOWLEDGMENTS}

We offer warm thanks to all participants for providing valuable feedback. This work has been supported by the Open Innovation Platforms spearhead project (A70202) and the Open City Model as Open Innovation Platform project (A71143), which are funded by the ERDF and the City of Oulu under the Six City Strategy program, and the COMBAT project (293389), funded by the Strategic Research Council at the Academy of Finland.

\section{REFERENCES}

[1] M Allen, H Regenbrecht, and M Abbott (2011). Smart-phone augmented reality for public participation in urban planning. In Proceedings of the 23rd Australian computer-human interaction conference, 11-20.

[2] E Almirall, M Lee, and J Wareham (2012). Mapping living labs in the landscape of innovation methodologies. Technology innovation management review, 2:(9), 12-18.

[3] ALVAR for Unity - ALVAR. VTT Technical Research Centre of Finland Ltd. Retrieved September 12, 2018 from http://alvar.erve.vtt.fi/doc/alvarunity/index.html

[4] RT Azuma (1997). A survey of augmented reality. Presence: Teleoperators \& Virtual Environments, 6(4), 355-385. DOI:https://doi.org/10.1162/pres.1997.6.4.355

[5] P Ballon and D Schuurman (2015). Living labs: concepts, tools and cases. Info, 17:(4). DOI:https://doi.org/10.1108/info-04-2015-0024

[6] B Bergvall-Kåreborn, C Ihlström Eriksson, A Ståhlbröst and J Svensson (2009). A milieu for innovation: defining living labs. In ISPIM Innovation Symposium.

[7] M Billinghurst, A Clark and G Lee (2015). A survey of augmented reality. Foundations and Trends ${ }^{\circledR}$ in Human-Computer Interaction 8:(2-3), 73-272.

[8] D Chatzopoulos, C Bermejo, Z Huang and P Hui (2017). Mobile augmented reality survey: From where we are to where we go. IEEE Access, 5, 6917-6950. DOI:https://doi.org/10.1109/ACCESS.2017.2698164. 
[9] A Dünser, R Grasset and M Billinghurst. 2008. A survey of evaluation techniques used in augmented reality studies. Human Interface Technology Laboratory New Zealand.

[10] ENoLL. Home. European Network of Living Labs. Retrieved September 12, 2018 from https://enoll.org/

[11] P. Geiger, M. Schickler, R. Pryss, J. Schobel, and M. Reichert. 2014. Locationbased mobile augmented reality applications: Challenges, examples, lessons learned. 383-394.

[12] V Gutiérrez, JA Galache, L Sánchez, L Muñoz, JM Hernández-Muñoz, J Fernandes, and M Presser. 2013. SmartSantander: Internet of things research and innovation through citizen participation. In The Future Internet Assembly, 173-186. DOI:https://doi.org/10.1007/978-3-642-38082-2_15.

[13] W Huang, M Pakanen, L Haukipuro, S Väinämö and L Arhippainen (2018). Motivate Online Users by Moderating and Providing Tasty Testing Experiences. In Proceedings of the 22st Conference of Open Innovations Association FRUCT, 8

[14] W Huang, https://www.patiolla.fi/en/

[15] Z Huang, P Hui, C Peylo and D Chatzopoulos (2013). Mobile augmented reality survey: a bottom-up approach. arXiv preprint arXiv:1309.4413.

[16] T Höllerer, S Feiner, T Terauchi, G Rashid and D Hallaway (1999). Exploring MARS: developing indoor and outdoor user interfaces to a mobile augmented reality system. Computers \& Graphics, 23:(6), 779-785.

[17] Infrastructure - Virtual Campus - Center for Ubiquitous Computing. Retrieved September 20, 2018 from http://ubicomp.oulu.fi/infrastructure virtual-campus/

[18] ISO DIS 9241-210:2010. Ergonomics of human system interaction - Part 210: Human-centered design for interactive systems. ISO, Switzerland.

[19] PW Jordan (Ed.). 2002. Designing pleasurable products: An introduction to the new human factors. Taylor \& Francis, London, UK.

[20] S Leminen, M Westerlund and A-G Nyström (2012). Living Labs as openinnovation networks. 2:(9), 6-11.

[21] V Lowndes, L Pratchett and G Stoker. 2001. Trends in public participation: part 2-citizens' perspectives. Public administration 79, 2 (2001), 445-455.

[22] Mapbox. Mapbox API Documentation. Retrieved September 12, 2018 from https://www.mapbox.com/api-documentation/

[23] R McCall and A-K Braun. 2008. Experiences of evaluating presence in augmented realities. Psychnology 6, 2: 157-163.

[24] A Niemelä. 2018. Mobile augmented reality client for citizen participation. Oulu, Finland.

[25] A Noyman, T Holtz, J Kröger, J Rainer Noennig and K Larson (2017). Finding Places: HCI Platform for Public Participation in Refugees' Accommodation Process. Procedia Computer Science 112, 2463-2472. DOI:https://doi.org/10.1016/j.procs.2017.08.180.

[26] V Paelke, S Büttner, H Mucha and C Röcker. 2017. A Checklist Based Approach for Evaluating Augmented Reality Displays in Industrial Applications. In International Conference on Applied Human Factors and Ergonomics, 225-234.
[27] BJ Pine and JH Gilmore (1998). Welcome to the experience economy. Harvard business review, 76, 97-105

[28] JKV Pismag, H Alawneh, C Adam, SA Rawashdeh, P Mitra, Y Chen and G Strumolo. 2017. Augmented Reality for Improved Dealership User Experience. SAE Technical Paper.

[29] Niantic. 2017. Pokémon GO. Niantic, Inc. Retrieved August 29, 2017 from https://play.google.com/store/apps/details?id=com.nianticlabs.pokemongo

[30] MEC Santos, J Polvi, T Taketomi, G Yamamoto, C Sandor and H Kato. 2015. Toward standard usability questionnaires for handheld augmented reality. IEEE computer graphics and applications 35, 5: 66-75.

[31] D Schmalstieg and T Hollerer. 2016. Augmented reality: principles and practice. Addison-Wesley Professional, Boston, Massachusetts, US.

[32] J Schumacher and K Feurstein (2007). Living Labs-the user as co-creator. In ICE 2007 Proceedings: 13th International Conference on Concurrent Enterprising, Sophia Antipolis, France.

[33] YA Sekhavat (2016). KioskAR. International Journal of Computer Games Technology, 4. DOI:https://doi.org/10.1155/2016/7690754

[34] TJ Soon. 2008. QR code. Synthesis fournal 2008, (2008), 59-78.

[35] M Sunnari, L Arhippainen, M Pakanen and S Hickey (2012). Studying user experiences of autostereoscopic 3D menu on touch screen mobile device. In Proceedings of the 24th Australian Computer-Human Interaction Conference, 558-561. DOI:https://doi.org/10.1145/2414536.2414622.

[36] Unity Technologies. Unity - Manual: AssetBundles. Retrieved September 12, 2018 from https://docs.unity3d.com/Manual/AssetBundlesIntro.html

[37] P Vorderer, W Wirth, F Ribeiro Gouveia, F Biocca, T Saari, L Jäncke, S Böcking, H Schramm, A Gysbers and T Hartmann. 2004. MEC Spatial Presence Questionnaire. Retrieved Sept 18: 2015.

[38] A POS Vermeeren, E Lai-Chong Law, V Roto, M Obrist, J Hoonhout and K Väänänen-Vainio-Mattila (2010). User experience evaluation methods: current state and development needs. In Proceedings of the 6th Nordic Conference on Human-Computer Interaction: Extending Boundaries, 521-530. DOI:https://doi.org/10.1145/1868914.1868973

[39] K Väänänen-Vainio-Mattila and M Wäljas (2009). Developing an expert evaluation method for user eXperience of cross-platform web services. In Proceedings of the 13th International MindTrek Conference: Everyday Life in the Ubiquitous Era, 162-169. DOI:https://doi.org/10.1145/1621841.1621871

[40] R Wetzel, R McCall, A-K Braun and W Broll. 2008. Guidelines for designing augmented reality games. In Proceedings of the 2008 Conference on Future Play: Research, Play, Share, 173-180.

[41] F Zhou, H Been-Lirn Duh and M Billinghurst (2008). Trends in augmented reality tracking, interaction and display: A review of ten years of ISMAR. In Proceedings of the 7th IEEE/ACM International Symposium on Mixed and Augmented Reality, 193-202. DOI:https://doi.org/10.1109/ISMAR.2008.4637362

[42] T Olsson, T Kärkkäinen, E Lagerstam and L Ventä-Olkkonen (2012). User evaluation of mobile augmented reality scenarios. Journal of Ambient Intelligence and Smart Environments 4:(1), 29-47. DOI:https://doi.org/10.3233/AIS-2011-0127 